Attitudes and Perceptions toward Affirmative Action Programs: An Application of Institutional Theory

\author{
Alex M. Susskind* \\ Cornell University \\ Robert A. Brymer \\ Florida State University \\ Woo Gon Kim \\ Florida State University \\ Hae Young Lee \\ Kyungsung University \\ Sean A. Way \\ Ecole hôtelière de Lausanne
}

Authors' Note

Alex M. Susskind,**corresponding author. School of Hotel Administration, Cornell University, 242 Statler Hall, Ithaca, NY 14853, United States. Email: ams76@cornell.edu. Tel.: +1 607 255 8839; fax: +1 6072554179 .

Robert A. Brymer, Dedman School of Hospitality, College of Business, Florida State University, 4114 University Center Building B, Tallahassee, FL 32306, United States. Email: rbrymer@fsu.edu. Tel.: +1 850644 8241; fax: +1 8506445565. 
Woo Gon Kim, Dedman School of Hospitality, College of Business, Florida State University, 4114 University Center Building B, Tallahassee, FL 32306, United States. Email: wkim@fsu.edu. Tel.: +1 850644 8242; fax: +1 8506445565 .

Hae Young Lee, Department of Hotel \& Tourism Management, Kyungsung University, 314-79 Daeyeon 3-dong, Nam-gu, Busan 608-736, South Korea. Email: hylee1228@ks.ac.kr. Tel.: +82 51663 4465; fax: +8251627 6830.

Sean A. Way, Lausanne Hospitality Research Center, Human Resource Management, Ecole hôtelière de Lausanne, Route de Cojonnex 18, 1000 Lausanne 25, Switzerland. Email: Sean.Way@ehl.ch. Tel.: +41 21785 1820; fax: +41 217851121 . 


\begin{abstract}
Due to the continuing controversy surrounding the use of affirmative action programs in organizational hiring and promotion practices, we conducted a study to model individuals’ attitudes, beliefs, and perceptions toward affirmative action (AA) programs considering social influences and an institutional theory framework. To conduct the study we surveyed 413 managers and supervisors from three large hotel companies in the pacific western and southeastern United States. Results indicate that institutional and social forces positively influenced participants' general perceptions of AA in the workplace.

Influences from social interaction exhibited a negative relationship upon attitudes toward the experience and practice of AA, specifically related to AA hires and organizational issues stemming from AA rather than the legislation itself.
\end{abstract}

Keywords: Affirmative Action, Institutional Theory, Institutional influence, Social Influence, Attitudes toward AA workers 


\section{Attitudes and perceptions toward affirmative action programs: An application of institutional theory}

\section{Introduction}

Affirmative action has long been the focus of debate among political, organizational, and social entities (Heilman et al., 1992; Kravitz and Platania, 1993; Parker et al., 1997). Affirmative action (AA) is a series of activities conducted by an organization that applies resources to eliminate or prevent discrimination from occurring in the workplace among protected classes (i.e., gender, ethnic minorities; Crosby et al., 2006; Leslie et al., forthcoming).Affirmative action is similar to Equal Opportunity, but differs because Equal Opportunity (EO) is reactive; when discrimination is identified, EO actions attempt to remove it (Crosby et al., 2006). Affirmative action comes about through actions, policies, and procedures put in place to prevent discrimination from occurring in the first place (Crosby et al., 2006; Leslie et al., forthcoming). Harrison et al. (2006) identified four structural features of research on AA in ascending order of prescriptiveness (that is the degree to which the AA action limits the discretion of the decision makers): (a)opportunity enhancement - uses focused recruitment and training to improve/enhance hiring pools with target group members;(b) equal opportunity - as noted above, is designed to eliminate existing discrimination by preventing target group members from being negatively evaluated; (c) tiebreak - gives preferential treatment to target group members over non-target members if they are equally qualified, and (d) strong preferential treatment - gives preference to target group members even if they are less qualified than non-target members. Based on this framework - through their meta-analysis - they found that prescriptiveness negatively affected individuals' perceptions of AA (Harrison et al., 2006), showing as organizations increase their efforts with AA that limit decision makers’ authority, negative affective toward AA becomes stronger.

Affirmative action continues to generate a broad range of attention in the organizationally based literature in terms of its utility in organizational practices and procedures and its influence upon organizations, their environments, and their members. Investigations into the presence and influence of 
AA in organizations have examined: (a) the historical and legal aspects of AA programs(Crosby et al., 2006; Kleiman and Faley, 1988; Robinson et al.,1992), (b) the social psychological implications of AA programs(Aquino et al., 2005; Braddock and McPartland, 1987; Caprariello et al., 2009; Fine, 1992; Kalev et al., 2006; Nacoste, 1987), (c) the implications of individuals' behaviors, attitudes, and perceptions ofcoworkers and self as influenced by AA programs (Harrison et al.,2006; Heilman et al., 1987, 1991, 1992, 1996; Heilman and Herlihy,1984; Kravitz and Platania, 1993; Leslie et al., forthcoming; Parkeret al., 1997; Shteynberg et al., 2011), and (d) the value or cost ofadding diversity to the organization (Kalev et al., 2006; Leslie et al., forthcoming; Niederle et al., 2013).

While these investigations have clearly heightened our under-standing of the presence and influence of AA in the workplace, the extent to which workers' perceptions and attitudes toward AA are influenced by broader-based institutional or social influences appears to be insufficiently studied in the literature on organizations. Our goal in this paper is to build on the existing organizational literature that examines AA and to examine the extent to which institutional and social forces are connected to attitudes about AA in the workplace. To that end, we will begin with a description of the relevant literature addressing AA and discuss the broader factors of institutional theory and social influence as it relates to AA. Ultimately, we will demonstrate that both institutional and social influences are connected to hotel managers’ perceptions of AA.

An institutional theoretical framework suggests that perceptions of organizational experiences, either in terms of organizational structure or discrete organizational phenomena, become rationalized through repeated exposure in a given organizational domain and influence individuals’ perceptions, beliefs, and actions (Drori and Honig, 2013; Scott, 1987; MacLean and Behnam, 2010; Sourouklis and Tsagdis, 2013; Weaver et al., 2003). Therefore, organizational actions and behaviors are conjointly influenced by extra-organizational factors and the extent to which they are legiti-mated in a given domain (Dacin et al., 2010; Doherty and Manfredi, 2001; Tolbert and Zucker, 1996). Institutional influences, in part, determine how individuals interpret and process elements of their surrounding environment. 
Affirmative action is a phenomenon that is particularly well suited to examination in terms of institutional forces upon individuals' perceptions and attitudes in organizational settings (Sourouklis and Tsagdis, 2013). Specifically, AA is rooted in legal-political actions which have been rationalized to remedy insufficient ethnic- and sex-based representation in the work-force (Crosby et al., 2006; Nacoste, 1994) identified by the forces regulating organizational action and behavior (e.g., hiring and pro-motion practices). Kalev et al. (2006) demonstrated that a formal responsibility structure in place for AA was connected to program effectiveness, showing that broader institutional influences can be made legitimate and deemed useful by an organization.

Gender and race discrimination in recruiting, hiring, performance evaluations, advancement, and disciplinary actions within the hospitality realm are still present. Slonaker et al. (2007) compiled a database from the Ohio Civil Rights Commission's employment discrimination claims, and the data analysis showed that approximately $5 \%$ of all claims were filed from within the restaurant industry. The two most common types of discrimination claims are those based on race and gender (Slonaker et al., 2007).In 2008, the Equal Employment Opportunity Commission (EEOC)received more than 30,000 race discrimination cases (Human Resources Issues in the Hotel Industry, http://hubpages.com/hub/HumanResources-Issues-in-the-Hotel-Industry). Considering the fact that the hospitality industry accounted for approximately one-third of the number of charges reported by the EEOC in 2009, the issue of discrimination in the workplace is still important to further explore, and it leads to challenges for hospitality human resource managers in hiring and promotion practices. Despite the importance of eliminating workplace discrimination, limited research has been conducted on the subject in the hospitality industry. The most prevalent hospitality research deals with the practical aspects of discrimination, such as the analysis of employment discrimination claims (Slonaker et al., 2007) and arbitration of employment discrimination lawsuits (Sherwyn, 2002).

Gröschl and Doherty (1999) examined ethnic minority policies at hotels in San Francisco, California. Their qualitative study gathered data via questionnaires and interviews from seven human resources directors at hotels identified as having the "best" diversity policies. A key finding of the 
research was that most human resources (HR) managers come from the operational side of the business, demonstrating a profit and production mindset rather than a strategic one. Consequently, most HR managers do nots pend adequate time strategically managing diversity beyond the point that law requires it. This includes AA policies, which encourage diversity but fail to deal with prejudice, inequality, and the development of talent. The article concludes that hotels should be more proactive in not only tolerating diversity, but valuing it. This conclusion connects to our work here in that to better manage diversity in the workplace; you need to understand how policies and procedures influence the attitudes, perceptions, and behaviors of organizational members affected by the policies (Weaver et al., 2003). This is also consistent with the findings of Shteynberg et al. (2011) who found that race-based AA in organizations led to perceptions of racism among Caucasians, which was then connected to their perceptions of unfairness in hiring and promotion practices in the organization.

Through their analyses of claims recorded by the Ohio Civil Rights Commission, Slonaker et al. (2007) reported and described several characteristics of these claims with regards to the hospitality industry. Five major findings from their analyses include: (1) a classification of the nature of discrimination claims by each of the four types of restaurants examined (i.e., national or regional quick service, by national or regional full service, local quick service, and local full service); (2) race claims by African Americans are three times disproportionate to their industry representation; (3) sexual harassment is claimed at a 69 percent higher rate in restaurants than in any other industry; (4) restaurant claimants face higher termination rates when claiming discrimination; and (5) claimants most frequently name their frontline supervisor as the cause of the discrimination. Based upon the findings, the researchers recommend corporations adapt their workplace cultures to be more diverse and thereby reduce discrimination claims. Additionally, they note that when individual (one instance/individual) discrimination turns into systemic (multiple instances/individuals) discrimination, government intervention and forced “assistance” will occur and could possibly negatively impact the company’s business objectives, which is more reactive (like EO) than proactive (like AA). As noted above, Kalev et al. (2006) found that having a formal organizational responsibility structure in place for AA had a stronger effect on 
program success. They further note that efforts for training and development of staff would likely be more successful within that said responsibility structure. It is important to reiterate that AA is intended to increase the ability of target groups to succeed in the workplace (Leslie et al., forthcoming).

Pinar et al. (2011) focused on gender differences in the Turkish hotel industry. A survey method was employed with a random sampling of associates at hotels. The analysis indicated that a "gen-der effect” exists in relation to education level and department, but not job position and age. Additionally, results indicate a gen-der difference in associate pay as well as gender segregation based upon the recruiter's gender (i.e., a female recruiter will offer a female a higher salary than a male recruiter would). Managerial implications of the study included a call to increase the number of women in "traditionally" male departments, sensitivity to recruiter-applicant mismatches, and an increase of employment opportunities for women (Niederle et al., 2013; Pinar et al., 2011).

These investigations highlight the prevalence of discrimination in hospitality-based businesses (MacVicar et al., 2000; Ng and Pine, 2003). To offer a better understanding about how individuals react to affirmative action - which is designed to counter such concerns in the workplace and protect workers this study examines the effects of institutional and social influences on hotel human resource professionals’ general perceptions and attitudes toward affirmative action programs. In the next section we discuss how institutional and social forces relate to workers' perceptions of AA in organizations and we present our research hypotheses.

\subsection{Environmental influences on individuals}

Staw and Sutton (1993) assert that a blend of micro-level psychological constructs, generally termed attitudes or perceptions, help explain the overarching attributes and behaviors that are perceptible in organizational contexts; these constructs are described as macro-organizational constructs. In a similar vein, Weick suggests that "the macro [level] is not a distinct existential level that emerges from micro events. Instead the macro [level] is constructed and pursued within the micro interaction” (Weick, 1993, p. 26). This can be interpreted to mean that whatever is considered an external influence (macro) to the 
organization (i.e., EEOC legislation or AA policies) also has roots and meaning created from within the organization and its members. For example, AA cannot exist (practically speaking) unless the organization and its members take the legislation into practice and attribute meaning to it (Drori and Honig, 2013; MacLean and Behnam, 2010; Tilcsik, 2010). Understanding external forces through their influence on internal variables pro-vides a means to understand the individual in a larger context. To provide an integrated view of both the internal and external environments, we introduce institutional theory as a means to examine how AA is perceived to function by individuals in organizations.

\subsection{The Individual}

The attitudes, beliefs, and values of people generally follow behavior (Salancik and Pfeffer, 1978). When certain behaviors or practices are sanctioned, such as conforming to AA hiring processes, individuals are more likely to accept those behaviors or practices and form their beliefs based on their exposure to certain behaviors (Pfeffer, 1981). Sanctioned behaviors or practices, however, can lead to negative reactions if the organizational actors do not see them as fair, legitimate, or useful (Drori and Honig, 2013; Heilmanet al., 1992; Kravitz and Platania, 1993) and consistent with their internal beliefs (Salancik and Pfeffer, 1978). When an institution-alized phenomenon leads to feelings of dissatisfaction, the internal members are likely to attribute their feelings of negativity toward the external institutionalizing force rather than specific internal actors (Tilcsik, 2010). A widely shared myth of AA programs rests on the assertion that women and ethnic minorities are selected because of who they are, as opposed to what they are capable of doing (Harrison et al., 2006; Heilman et al., 1992; Kravitz and Platania, 1993; Leslie et al., forthcoming; North craft and Martin, 1982; Parker et al., 1997; Plous, 1996). These views, which may or may not be based on true observed characteristics or qualities, can incite the stigmatization of affirmative action hires and their abilities (Heilman et al., 1992, 1996; Leslie et al., forthcoming). The discounting of an individual's qualifications to perform on the job as a function of sex and/or race adds to the stigmas that already exist in society. As such, when a worker is associated with some form of AA, based on assumed sub-optimal qualifications that are legitimized, a negative image is 
likely to be perpetuated (Aquinoet al., 2005; Caprariello et al., 2009; Heilman et al., 1992; Plous, 1996) for the legislation, the institutionalizing force, the organization, and/or the individual specifically. In essence, these negative perceptions then become institutionalized.

Conversely, if behaviors or practices positively influence an individual's beliefs in terms of attitude toward the behavior, the individual is likely to: (a) develop a heightened awareness of the topic, (b) relate favorably to the topic, and (c) express satisfaction with the topic (Garib, 2013). In terms of institutionalization, if organizationally based behaviors or practices influence an individual's beliefs, it is likely that positive perceptions will be attributed not only to the external force introducing the behavior or action, but also to the organizational and individual actors involved in the behavior or practice (Dacin et al., 2010; Drori and Honig, 2013).

\subsection{Institutional and social influences and affirmative action}

Interrelationships are present among individuals, organizations, and the environments in which they coexist. As noted by Dacin: "the institutional framework is primarily concerned with an organization's relationship with the institutional environment, the effects of social expectations (prescriptions) on an organization, and the incorporation of these expectations as reflected in organizational characteristics” (1997, p. 48). Organizations, and hence individuals within organizations, are faced with new challenges in order to survive. For survival and legitimation, from the perspective of both the individual and the organization, new practices and procedures need to be incorporated into organizational behavior, as they emerge through the prevailing rationalized societal forces (Dacin, 1997; Meyer and Rowan, 1977). As noted above, if AA practices and procedures (e.g., behavior) are accepted at the individual level, they are likely to be perceived as positive organizational elements (Dacin et al., 2010; Drori and Honig, 2013).

For example, prior to the enactment of the Americans with Dis-abilities Act of 1990 (ADA), organizations and their members were required to follow employment and hiring guidelines specified under Title VII of the Civil Rights Act (1964) and the Rehabilitation Act of 1973, as regulated by the 
Equal Opportunity Employment Commission (EEOC). These amendments to AA-type legislation provide a recent example of programs institutionalized into organizations due to a broader perceived societal need not necessarily explicit at either the individual or organizational level, nor tied directly to actual production processes in organizations (Meyer and Rowan, 1977; Tolbert and Zucker, 1996). With the addition of the ADA, organizations (and hence individuals) are now required to adhere to the "revised" set of requirements in addition to the legislative elements that were not amended. Not conforming to the regulations can threaten the existence of the organization (Meyer and Rowan, 1977) and/or the jobs of those not willing to conform to the laws. As a result, the regulation (ADA) is likely to become rationalized at the organizational level and deemed as legitimate by the organization with the intent of affecting its entire member-ship. A recent related example can be found in the financial services sector. As reported by MacLean and Behnam (2010), a financial services firm decoupled itself from a set of compliance regulations in their day-to-day operations. This separation created a false sense of compliance and led to insufficient compliance oversight, allowing employees to engage in deceptive, illegal sales practices. The lesson is, if an organization does not fully embrace external regulation and have a structure to ensure compliance and acceptance of said regulation in day-to-day operations, a disconnect will likely emerge and threaten the legitimacy of the organization.

However, as suggested by Dacin, and in the case of AA, isomorphism with an external environment is not strictly a function of organization to organization interrelationships, but "result from pressures exerted by broader societal expectations” (1997, p. 50).The effects of such rationalized components on organizations are great (Meyer and Rowan, 1977; Tilcsik, 2010), but are often not examined at the individual level (Tolbert and Zucker, 1996). When internalizing externally legitimated elements (such as AA legislation), the legitimated formal structure (the organization) attempts to increase the commitment of internal participants (the organizational members) and the legitimacy of external constituents, such as the EEOC (Tolbert and Zucker, 1996). When an organization is required to use EEOC guidelines in their hiring practices, those who accept the responsibility of compliance to the guidelines can use the guidelines to direct their behavior as a perceived function of their job, while 
decoupling from any existing guidelines which may conflict. Over time, the repeated use of the guidelines becomes habituated and creates a sense of ritual significance, which validates, legitimatizes, and maintains a preordained organizational image (Dacin et al., 2010; Meyer and Rowan, 1978) such as "Smith and Company is an Equal Opportunity Employer."

The institutionalized image, however, may not be isomorphic to the beliefs and attitudes of the individual actors in the organization (Meyer and Rowan, 1977; Scott, 1987). The organization will then be faced with the conflict of conforming to the institutionalized rules and the external constituencies or to the satisfaction of the internal actors (MacLean and Behnam, 2010; Meyer et al., 1992). This conflict among internal and external forces signifies a lack of ability to coordinate interdependent activities and brings to light disagreements about the ends or goals of the social system in relation to the organizational actors (MacLean and Behnam, 2010; Pfeffer and Salancik, 1978; Tolbert and Zucker, 1996). Both internal and external groups are important for organizational survival and legitimacy (Drori and Honig, 2013; Meyer et al., 1992), and this conflict would not exist without interdependence of individual actors, organizations, and society at large in the performance and execution of their organizational duties (Pfeffer and Salancik, 1978). The organization can dissolve in conflict and illegitimacy if the internal and external understandings of the regulation are not aligned (MacLean and Behnam, 2010; Meyer and Rowan, 1978).This suggests that to understand the inner workings of institutionalization, individual level perceptions and beliefs are important to provide insight into how phenomena evolve from disenfranchised concepts to legitimized, rationalized organizational components and behaviors.

Numerous theoretical descriptions of institutionalization have identified social affect as a consequential influence (Kamens, 1977; Meyer and Rowan, 1977; Scott, 1995; Tilcsik, 2010; Tolbert and Zucker, 1996). This suggests that social influences or information gathered from intra-organizational sources, such as co-workers, and extra-organizational sources, such as family, friends, political groups, or religious groups (Aquino et al., 2005; Caprariello et al., 2009; Jablin, 1987; Harrison et al., 2006;

Nacoste, 1994), influence the perceived outcomes of institutionalization at the individual level. The Social Information Processing Model (cf. Salancik and Pfeffer, 1978) and Social Learning Theory (cf. Bandura, 
1977) provide theoretical justifications to include social influences along with the study of institutionalism. From a social information processing perspective, an individual's perception of an organizational phenomenon (AA in this case) would be influenced by exposure to behavior, norms, and values espoused by extra-work relationships, co-workers, and organizational constituents (Aquinoet al., 2005; Caprariello et al., 2009). From a social learning perspective, individuals' perceptions of AA would be influenced to the extent that AA appears to be efficacious and leads to apparent, useful outcomes (Kalev et al., 2006).

Few studies have examined the influence of social forces on individuals' perceptions of AA and AA hires. What has been reported shows that: (a) social structure is related to stereotypes, which influences prejudice and discrimination regarding AA and AA hires (Caprariello et al., 2009; Shteynberg et al., 2011); (b) conservative political ideology and a Republican party affiliation were negatively associated with views of AA (Harrison et al., 2006), and (c) there are sociodemographic differences (i.e., gender, age, education) in how people view AA and AA hires (Crosby et al., 2006).

In sum, behavior and action become institutionalized through socially shared meanings that individuals either embrace or reject (Dacin et al., 2010; Scott, 1987; Tolbert and Zucker, 1996) based on cognitive schemas of AA and its influence (Aquino et al., 2005; Harrison et al., 2006; Nacoste, 1994).

\section{Research model and hypothesis}

To test the propositions forwarded in this investigation, the following research model is proposed (see Fig. 1): as exogenous components in the model, institutional influence and social influence lead to general perceptions of AA programs, which in turn lead to attitudes toward AA workers in organizations. The key contribution of this investigation is the concurrent examination of institutional and social influences on individuals’ perceptions of abroad-based organizational phenomenon. 


\subsection{Institutional influence and AA perceptions}

Institutional influence is conceptualized as the extent to which an individual believes that external forces, such as the government or the EEOC, are responsible for AA legislation, as opposed to individuals or an employing organization. Drawing on the literature presented above, institutional influence is hypothesized to be positively related to general perceptions of AA programs when measured at the individual level, as individuals initially form their perceptions of AA based on such influences. Thus, the following hypothesis is proposed:

Hypothesis 1. Institutional influence is positively related to general perceptions of AA programs.

\subsection{Social influence and AA perceptions}

Social influence is defined as information gathered from intra-organizational sources, such as friends or co-workers, and extra-organizational sources, such as family, friends, or religious groups, that lead to the development of a "social schema" of AA and its components. From the existing literature described above, the following hypothesis is formulated:

Hypothesis 2. Social influence is positively related to general perceptions of AA programs.2.3.

General perceptions of AA

\subsection{General perceptions of AA programs and attitudes toward AA workers}

General perceptions of AA programs are represented as an individual's belief, or lack thereof, that AA programs are beneficial and useful to organizations, individuals, and society as a whole. Once general perceptions are formed about AA, an individual can then relate those perceptions to specific objects, such as AA workers in organizational settings. Attitudes toward AA workers in organizations represent an individual's impressions about workers perceived to be hired through AA programs and about organizations using AA in their practices and procedures. Attitudes toward AA workers are distinctly different from general perceptions of affirmative action because they refer to identifiable evaluative objects (i.e., coworkers). Thus, the following hypothesis is suggested: 
Hypothesis 3. Attitudes toward AA workers in organizations will be positively related to individuals' general perceptions of AA workers.

\section{Method}

\subsection{Participants}

Four hundred and thirteen managers and supervisors employed in three American hotel companies in one southeastern and six west-coast metropolitan areas were surveyed for this investigation using a cross-sectional research design. The participants were sampled during management development seminars at their places of work and were asked to complete a questionnaire that assessed their perceptions of and attitudes toward both their work and non-work environments during a scheduled break specifically designed for questionnaire completion. We selected this group of participants because they were currently employed in managerial/supervisory roles and as a result were responsible for the hiring, training, and development of their staff. The participants were guaranteed strict anonymity in their responses and were assured that neither their names nor the names of their companies would appear, under any circumstances, on any report generated from the data.

The participants can be described as approximately 44 per-cent female, between the ages of 20 and $66(\mathrm{M}=34.77, \mathrm{SD}=8.6$, median = 34). The sample's racial composition can be described as50 percent Caucasian ( $n=207), 19$ percent Asian $(n=78)$, five per-cent Hispanic $(n=21)$, four percent Native American ( $\mathrm{n}=16)$, and 2percent African American $(\mathrm{n}=8)$. Nine percent selected the "other” race category $(n=37)$, and 11 percent elected to leave the question blank $(n=45)$. The majority of the respondents reported earning degrees from post-secondary institutions: 41 percent reported four-year degrees $(n=169), 12$ percent reported associate or technical degrees $(n=51)$, and one percent reported graduate degrees $(n=5)$. Twenty-two percent of the participants indicated that they had attended some college but earned no degree $(n=94), 11$ percent indicated that they completed high school only $(n=46)$, two per-cent reported less than a high school education $(n=6)$, and eleven percent opted to leave the question blank $(n=42)$. The participants reported a mean tenure of 5.33 years (median $=3.5)$ of 
employment within their current companies. Seven percent of the participants hold positions in food and beverage management within the hotels $(\mathrm{n}=29)$ and 93 percent hold positions in hotel operations and management $(\mathrm{n}=384)$.

\subsection{Measurement}

Since there were no validated measures for the majority of the constructs we introduced here, we conducted a pilot study to create and validate survey items. First, we developed survey items from the conceptual definitions provided by previous related studies. Specifically, we developed 11 questions to represent institutional influence from the works of Meyer and Rowan $(1977,1978)$ and Meyer et al. (1992); we developed 13 items to represent social influence from the works of Bandura (1977) and Jablin (1987); and we developed 11 items representing general perceptions of AA and 8items representing attitudes toward AA workers from the works of Heilman et al. (1992, 1996) and Kravitz and Platania (1993). We created more survey items than needed to allow us to remove items as the content and construct validation process progressed. After the creation of the survey items, three academic scholars judged the overall quality and relevance of the questionnaire items. Based on the collected comments, modifications were made to the survey items to improve readability and conceptual match of the items to the constructs of interest.

Next, we pre-tested the survey items among a group of 292undergraduate business students who, at the time of survey administration, were enrolled in courses in organizational behavior and human resources management at two large research-based institutions (one in the Midwestern and one in the Southeastern United States). We selected these participants because they would be familiar with the general tenants of AA through their coursework, but would likely have little direct work experience surrounding the subject. Participants were asked to indicate their level of agreement with each survey item on a five-choice Likert-type metric(strongly agree, agree, neutral, disagree, and strongly disagree). We then examined the four scales' factor structure through exploratory factor analysis with a Varimax rotation and reliability analysis. The factor analyses revealed that several items did not align with the a 
priori defined constructs. Some items were deleted due to single-item factor formation, low loading or cross loading, or conceptual misspecification (mis-loading).

As a result of the pilot study we retained a: (a) five-item representation of institutional influence $($ Cronbach’s ، $=.72)$, (b) four-item measure of social influence (Cronbach’s ، $=.78)$, (c) five-item representation of general perceptions of AA (Cronbach's ، $=.90)$, and (d) four-item measure of attitudes toward AA workers in organizations (Cronbach's $،=.78$ ). The final four factor model explained a total 61.45 percent of the variance in the model and demonstrated sound measurement reliability. Following the pilot study we used the items we developed to survey the managerial sample described above.

\subsection{Socio-demographics}

To further examine the demographic composition of our sample of 413 managers we looked at the relationship between the participants’ race, education, age, and sex the variables in Fig. 1 (i.e., institutional influence, social influence, general perceptions of AA, and attitudes toward AA workers in organizations). To do so we applied one-way analysis of variance (ANOVA) with a post hoc Duncan’s multiple range test to examine the effects of race and education, we used correlational analysis to examine the effect of age, and we used an independent sample t-test to look at the effect of sex.

\subsubsection{Race}

The participants' race was only significant in concert with the social influence variable (F [5,353] $=5.28, \mathrm{p}<.001)$. The Duncan multiple range test showed that African Americans reported the lowest level of social influence $(M=1.59)$ and were significantly different from the other five categories of race which had means ranging from $M=2.37$ for Caucasians up to $M=2.73$ for Native Americans.

\subsubsection{Education}

The participants' educational level was significantly related to social influence $(\mathrm{F}[5,344]=2.80$, $\mathrm{p}=.02)$ and attitudes toward AA workers in organizations $(\mathrm{F}[5,355]=4.87, \mathrm{p}<.001)$. The Duncan multiple range tests showed that those with graduate degrees reported the lowest level of social influence $(M=2.17)$ and were significantly different from those who had not completed high school who reported 
the highest level $(\mathrm{M}=3.08)$. The participants reporting the other 4 levels of education were not significantly different from each other regarding social influence. The Duncan multiple range tests also revealed that participants who did not complete high school reported the lowest level of attitudes toward AA workers in organizations ( $\mathrm{M}=2.60)$ which was significantly different from the other 5 categories of education measured. Educational level was not significantly related to perceptions of institutional influence or general perceptions of AA.

\subsubsection{Age}

The participants’ age was significantly correlated with social influence $(\mathrm{r}=-.12, \mathrm{p}=03)$ and attitudes toward AA workers in organizations $(\mathrm{r}=-.13, \mathrm{p}=01)$, showing that older respondents reported lower levels social influence and attitudes toward AA workers in organizations. Institutional influence and general perceptions of AA were not significantly correlated with age $(r=-.03, p=64$ and $r=.05, p=$ 34, respectively).

\subsubsection{Sex}

Females reported a higher level of institutional influence than their male counterparts ( $\mathrm{t}$ [353] = $-3.90, \mathrm{p}<.001, \mathrm{M}=3.67$ and $\mathrm{M}=3.37$, for females and males respectively). Females also reported a higher level of general perceptions of AA $(\mathrm{t}[363]=-2.86, \mathrm{p}=.005, \mathrm{M}=3.57$ and $\mathrm{M}=3.32$, for females and males respectively) and higher level attitudes toward AA workers in organizations $(\mathrm{t}[357]=-2.50, \mathrm{p}$ $=.01, \mathrm{M}=3.57$ and $\mathrm{M}=3.40$, for females and males respectively). Social influence was not significantly different for females and males.

\subsection{Data Analysis}

The latent model presented as Fig. 1 was tested with LISREL8.2 using maximum likelihood estimation (Jöreskog and Sörbom, 1996). As recommended by Anderson and Gerbing (1988), the scale validity was first estimated through a measurement model and then the proposed relationships were examined through a structural model. Institutional influence and social influence were treated as exogenous variables in the structural model, while general perceptions of AA and attitudes toward AA 
workers in organizations were the endogenous variables. Overall model fit was assessed based on several different criteria, such as global chi-square, goodness-of-fit index (GFI), comparative fit index (CFI), non-normed fit index (NNFI), and root mean square error of approximation (RMSEA). An additional model comparison was made between the direct (partial mediation) model and indirect (full mediation) model to examine the direct and indirect effects (through general perceptions toward AA) of institutional and social influence on attitudes toward AA workers in organizations. The tests of the direct and indirect models are presented below as Figs. 2 and 3, respectively.

\section{Results}

\subsection{Measurement Model}

The overall quality of the measurement model was evaluated using confirmatory factor analysis (CFA). The results showed that the measurement model provided a good fit to the data $(2=210.01, \mathrm{df}=$ $95, \mathrm{p}<.001 ; \mathrm{GFI}=.94 ; \mathrm{CFI}=.98 ; \mathrm{NNFI}=.97, \mathrm{RMSEA}=.045)$. In support of convergent validity, all items loaded on their respective constructs and the lowest t-value was 9.24. The composite reliabilities surpassed the minimum criterion of .60, thus indicating the internal consistency of each construct. From a more conservative approach, all average variance estimates were greater than the minimum value of .50 (Fornell and Larcker, 1981). Two items for institutional influence and one item for attitudes toward AA workers in organizations were dropped due to the weak contributions to internal consistency (see Table 1). To prove discriminant validity, the squared correlations were compared with the average variances; the squared correlations were lower than the average variances, demonstrating discriminant validity (the highest $\phi=.59, \phi 2=.35$ ) (see Table 2).

\subsection{Structural Model}

Since the scale validity was confirmed through the measurement model, the hypothesized relationships were tested using the structural model. The hypothesized model produced a good fit to the data $(\mathrm{x} 2=216.69, \mathrm{df}=97, \mathrm{p}<.001 ; \mathrm{GFI}=.94 ; \mathrm{CFI}=.98 ; \mathrm{NNFI}=.97, \mathrm{RMSEA}=.055)$. The structural 
model explained 39\% of the variance in general perceptions of AA and $17 \%$ of the variance in attitudes toward AA workers in organizations. As Table 3 indicates, both institutional influence $(\mathrm{y} 11=.55, \mathrm{t}=$ 9.21, $\mathrm{p}<.001)$ and social influence $(\mathrm{y} 12=.21, \mathrm{t}=3.91, \mathrm{p}<.001)$ were significantly related to general perceptions of AA, supporting $\mathrm{H} 1$ and $\mathrm{H} 2$. General perceptions of $\mathrm{AA}(\beta 21=.41, \mathrm{t}=6.37, \mathrm{p}<.001)$ also had a significantly positive path to attitudes toward AA workers in organizations, supporting H3.

\subsection{Alternative Model}

To further examine the direct effect of institutional and social influences on attitudes toward AA workers in organizations, the proposed indirect model (full mediation model) was compared with the direct model (partial mediation model) by inserting two directs paths from institutional and social influence to attitudes toward AA workers in organizations. The revised model (direct model) presented in Fig. 2 demonstrated a better fit to the data $(\Delta 2=6.68, \mathrm{df}=2, \mathrm{p}<.05)$. Specifically, institutional influence remained a significant positive influence upon general perceptions of AA $(y 11=.55, t=9.18, \mathrm{p}<.001)$ but not upon attitudes toward AA workers in organizations $(\mathrm{y} 21=.00, \mathrm{t}=.02$, n.s.). Social influence was significantly related to both general perceptions of AA and attitudes toward AA workers in organizations $(\mathrm{y} 12=.22, \mathrm{t}=4.02, \mathrm{p}<.001 ; \mathrm{y} 22=-.16, \mathrm{t}=-2.61, \mathrm{p}<.01$, respectively). The relationship between general perceptions of AA and attitudes toward AA workers in organizations also remained positive and significant $(\beta 21=.46, \mathrm{t}=5.49, \mathrm{p}<.001)$. Furthermore, though it was small, the variance in attitudes toward AA workers increased by 2 percent from the original model ( $\mathrm{R} 2$ for indirect model $=.17$ and R2for direct model $=$.19) (Bagozzi and Lee, 2002).

It should be noted that the relationship between social influence and attitudes toward AA workers in organizations was negative, while the relationship between social influence and general perceptions of AA remained positive. This relationship can be interpreted to mean that individuals readily relate social influences to the formation of general positive perceptions of AA, but do not view those influences as positive when building specific favorable attitudes toward the experience and practice of AA in terms of workers and organizational settings. However, as demonstrated in Fig. 3, the presence of social influence 
upon specific attitudes toward AA workers was also indirectly linked through general perceptions. In sum, both institutional and social forces proved to be significant antecedents of general perceptions of AA, and social influence demonstrated a strong negative influence upon specific attitudes toward AA in organizations.

\section{Discussion and Conclusion}

Acknowledging the recommendations of Tolbert and Zucker (1996), this investigation sought to examine the influence and presence of institutional forces at the individual level. The results suggest that institutionalism can be identified and modeled at the individual level, and social influences are complementary to the process of institutionalization. In this study, a means to assess the institutional and social influences of AA was proposed and tested among managerial and supervisory personnel working in hotels. The results indicated that a reliable, generalizable approach to examining the effects of institutional and social influences on organizational phenomena exists.

\subsection{Implications}

The participants responded consistently to the measurements of institutional influence, social influence, general perceptions, and attitudes toward AA workers. Individuals, in this case, perceived AA as being created and regulated by external forces, meaning that the identified institutional forces were viewed as the means by which AA is introduced into organizations. From that point, individuals formed an understanding of the phenomenon expressed in terms of both general perceptions and specific attitudes. Therefore, the process of institutionalization is reliant upon the acceptance of the individual, with the institutional force creating a buffer for the individual in the event that the institutionalized phenomenon is not isomorphic with his/her cognitive schema of beliefs (Garib, 2013; Ng and Pine, 2003).

It was hypothesized that social influence would act as a joint influence on general perceptions of AA in the structural path models. Social influence acted as a positive influence upon general perceptions of AA, as expected, but unexpectedly acted as a negative influence upon attitudes toward AA workers in 
organizations. A negative relationship between social influence and specific attitudes toward AA suggests that individuals do not positively associate the formation of specific attitudes toward AA with social forces. This finding suggests that social influences can lead the way to forming negative perceptions about workers believed to be associated with AA. However, general perceptions of AA appear to be positively related to social influences. These findings imply that apart from their positive perceptions toward AA, individual hotel managers may develop prejudiced beliefs about AA workers by referencing social influences from close relationships. When they are less motivated to accept social forces, hotel managers are not likely to comply with the referents by developing unfavorable feelings about AA workers. More rational management strategies are thus recommended to decrease the direct negative impact of social influence. Hotel managers and supervisors should focus on high-lighting unique values added to an organization by AA workers. The diverse cultural backgrounds, knowledge, and work experiences of AA workers can be viewed as assets that improve business competitiveness (Garib, 2013). This idea seems particularly relevant for the hospitality industry given the traditionally diverse backgrounds of both employees and their guests. In addition, hotels can ensure individual employees take part in the selection and recruitment process; this would make the hotel employees more aware of the AA workers' values, consequently helping them cope more effectively with any negative feelings they may have toward AA workers, regardless of sources of influence. Such management efforts may lead employees to form more positive perceptions of AA, which could then mitigate the unintended social influences (Iverson, 2000; Harrison et al., 2006; Leslie et al., forthcoming; Sourouklis and Tsagdis, 2013). While stereotyping, discrimination, and stigmatization have been identified in organizations in connection to AA (cf. Leslie et al., forthcoming; Shteynberg et al., 2011), there is some evidence to show that organizations benefit from AA. In an experiment, Niederle et al. (2013) imposed an AA quota on entrants into a com-petition to ensure that an equal number of men and women entered and succeeded. As a result of the prescribed quota (cf. Harrison et al., 2006) the pool became more populated by women and hence qualified women - and the effect on overall performance was nonsignificant (Niederle et al., 2013), showing the costs of adding diversity were limited. This is a supply-side argument, where most of 
the research in this domain focuses on issues of demand (Niederle et al., 2013). What this highlights is that securing a broader and more diverse pool (supply) can/should yield the same quality per-formers in the end, affect aside.

To increase future benefits from AA practices, managers and supervisors should consider diversifying their applicant pools, and concurrently consider more practical ways to fortify individual employees' general perceptions of AA. Influences from institutional and social powers should be utilized together to form employees' general beliefs about AA, though individuals use institutional forces rather than social forces to rationalize the existence of extra-organizational phenomena (such as AA). Institutional and social influences can be viewed as separate, yet parallel. Thus, segmented communication approaches rather than mass promotional approaches toward AA would be more effective, since the relative influence of institutional and social interaction may vary depending on each employee’s demographic or job-related characteristics. Consequently, such efforts by businesses toward AA practices would be linked to long-term success through improved acceptance both from employees who are aware of the value of AA policies and practices and from customers who place their values on diversity or equality. A similar parallel can be drawn from the new “Affordable Health Care Act.” As workers learn more about how the legislation works and how it affects them personally and directly, positive perceptions have been reported when compared to workers who do not fully understand how the legislation works and how it affects them directly (Consumers Union, 2013).

Lastly, it is important to note that there were several differences in the socio-demographic characteristics of our sample of managers and how they reacted to AA programs. First, women reported higher levels of institutional influence, general perceptions of AA, and attitudes toward AA workers in organizations than their male counterparts, but reported no differences in social influences; second, older workers showed lower levels of influence from social forces and a lower perception of AA workers in organizations, but age was not significantly associated institutional influence or general perceptions of AA; third educational level was significantly related social influence and attitudes toward AA workers showing that those participants with a graduate level education reported the lowest level of influence from 
social forces, while those without a high school education reported the highest level of influence. Likewise those without a high school diploma reported the most negative views of AA workers in organizations; finally, African American managers reported a significantly lower level of social influence compared to the other five categories of race we sampled. These findings highlight the need to better target programs, communication, and messaging to ensure that each demographic group receives the right message to fully understand how AA programs are designed and for what purpose and desired outcomes.

\subsection{Limitations}

A cross-sectional approach using self-report instruments was used to conduct this study. We justify the use of this approach based on several considerations, acknowledging the importance of conducting multi-trait, multi-method research wherever appropriate (Howard, 1994; Spector, 1994). A major goal of this investigation was to assess the influence of environmental factors on individuals' perceptions of AA. However, no suitable measures existed to assess the constructs presented in our theoretical model at the individual level, which created a need to measure and test these constructs. The constructs presented herein are all measured with mostly new items, are strictly attitudinal and perceptual in nature, and do not directly address respondents' behavioral characteristics, which might be better measured through objective, direct observations from others (Schmitt, 1994). In reference to the use of self-report measurements (which he deemed no longer appropriate in stress research), Schmitt (1994, p. 395) asserted "that such use[of self-report measures] might be more acceptable in assessing the influence of affirmative action policies on workers' opinions of individuals who might benefit from those policies.” Clearly this contention alone is not a justification to abandon the application of multi-method measurement in AA research, but tempered with the noted concerns, it provides some guidance for the development and use of concepts still in their infancy.

Additionally, due to the sensitive nature of the use of AA pro-grams in organizations (especially in the Pacific Western United States during the time of data collection), the participating organizations were reluctant to provide specific information concerning AA programs in place in their establishments as 
additional independent and dependent measures to be used in this study. Therefore, we mutually agreed upon a non-obtrusive measurement instrument, mitigating the survey length and the sensitivity of the questions presented to meet the needs of the three sponsoring companies as well as the research investigation. These decisions were not made for convenience, but for simplification of the data collection process based on the sponsoring organizations' concerns.

The noted constraints highlight the importance of adjusting field-based research designs to meet the needs of the participating organizations. Nevertheless, research designs should include multiple approaches where appropriate in order to limit the possibility of percept-percept inflation in survey responses (Crampton and Wagner, 1994; Schmitt, 1994; Spector, 1994).

Lastly, social desirability remains a concern in the use of self-report measurement when addressing a sensitive topic such as AA (Ones et al., 1996). To attempt to deal with this concern, several "reverse-coded" items were included in the questionnaire to help contrast the sensitivity of the questions and how the respondents might respond to them. It should be noted that the sound reliabilities and the strong interrelationship among general perceptions of AA and specific attitudes toward AA suggest that the study participants consistently responded to the potentially sensitive items presented. In this study, it appears that the respondents were more likely to identify institutional forces as positive influences on AA when compared to social forces, further supporting an institutional framework. One cannot, however, discount the role that social influence played in these investigations. Regardless, great care should be taken in the presentation of sensitive topics to avoid response bias in survey research as influenced by social desirability.

\subsection{Future Research}

The findings of this study highlight several directions for future research. First, the measurement of institutionalization at the individual level is in its infancy. Our understanding of the process of institutionalization will be greatly enhanced through further examination of broad-based extraorganizational phenomena that can be traced to the individual level. Given the findings, future research 
should address the issue of multi-method measurement in the assessment of individuals' reactions to AA in terms of institutional and social influences. Researchers should keep in mind, however, that the core of these findings is based on perceptions and attitudes that are not easily measured through observational techniques (Schmitt, 1994). Future research designs might include organizational factors such as the number of AA hires in a given setting, the organizational programs in place to increase minority representation, and the performance ratings of both minority and non-minority personnel. All of the aforementioned observational items are likely to increase our understanding of AA in organizations and how institutionalization influences members’ perceptions and attitudes.

Similar to legislative mandates, changes in organizational technology are often introduced by forces external to the organization. Issues such as technological innovation, adoption, and use in organizations have been previously examined through a "diffusion” framework (cf. Rogers, 1983; Fulk et al., 1987), but have yet to be examined in terms of individual-level reactions to both institutional and social forces. This investigation highlighted the ever present but equivocal role social forces play in individuals’ perceptions and attitudes of broad-based institutional phenomena such as AA. Future researchers should continue to examine social influences along with institutional forces to provide a greater understanding of extra-organizational influences upon organizational behaviors and attitudes. 


\section{References}

Anderson, J.C., Gerbing, D.W., 1988. Structural equation modeling in practice: are view and recommended two-step approach. Psychol. Bull. 103 (3), 411-423.

Aquino, K., Stewart, M.M., Reed III, A., 2005. How social dominance orientation and job status influence perceptions of African American beneficiaries. Pers. Psychol.58, 703-744.

Bagozzi, R.P., Lee, K., 2002. Multiple routes for social influence: the role of compliance, internalization, and social identity. Soc. Psychol. Q. 65 (3), 226-247.

Bandura, A., 1977. Self-efficacy: toward a unifying theory of behavioral change. Psychol. Rev. 84, 191215.

Braddock, J.H., McPartland, J.M., 1987. Social science evidence and affirmative action: a reply to the commentators. J. Soc. Issues 43, 133-143.

Caprariello, P.A., Cuddy, A.J.C., Fiske, S.T., 2009. Social structure shapes cultural stereotypes and emotions: a causal test of the stereotype content model. Group Process. Intergr. Relat. 12 (2), $147-155$.

Consumers Union, 2013. The Affordable Care Act: The First Year, Down-loaded on Sept. 16, 2013 from: http://www.wesleyan.edu/healthservices/insurance/healthcarereformcollegehealth.pdf

Crampton, S.M., Wagner III, J.A., 1994. Percept-percept inflation in microorganizational research: an investigation of prevalence and effect. J. Appl. Psychol. 79, 67-76.

Crosby, F.J., Iyer, A., Sincharoen, S., 2006. Understanding affirmative action. Annu. Rev. Psychol. 57, 585-611.

Dacin, M.T., 1997. Isomorphism in context: the power and prescription of institutional norms. Acad. Manage. J. 40, 46-81.

Dacin, M.T., Munir, K., Tracey, P., 2010. Formal dining at Cambridge colleges: linking ritual performance and institutional maintenance. Acad. Manage. J. 53 (6), 1393-1418.

Doherty, L., Manfredi, S., 2001. Women’s employment in Italian and UK hotels. IJHM20, 61-76. 
Drori, I., Honig, B., 2013. A process model of internal and external legitimacy. Org. Stud. 34 (3), 345376.

Fine, T.S., 1992. The impact of issue framing on public opinion: toward affirmative action programs. Soc. Sci. J. 29, 323-334.

Fornell, C., Larcker, D.F., 1981. Evaluating structural equation models with unobservable variables and measurement error. J. Marketing Res. 18 (2), 39-50.

Fulk, J., Steinfield, C.W., Schmitz, J., Power, J.W., 1987. A social information processing model of media use in organizations. Commun. Res. 14, 529-552.

Garib, G., 2013. Leisure managers’ perceptions of employee diversity and impact of employee diversity. Int. J. Hospital. Manage. 32, 254-260.

Gröschl, S., Doherty, L., 1999. Diversity management in practice. Int. J. Contemp. Hospital. Manage. 11 (6), 262-268.

Harrison, D.A., Kravitz, D.A., Mayer, D.M., Leslie, L.M., Lev-Arey, D., 2006. Understanding attitudes toward affirmative action programs in employment: summary and meta-analysis of 35 years of research. J. Appl. Psychol. 91 (5), 1013-1036.

Heilman, M.E., Block, C.J., Lucas, J.A., 1992. Presumed incompetent? Stigmatization and affirmative action. J. Appl. Psychol. 77, 536-544.

Heilman, M.E., Herlihy, J.M., 1984. Affirmative action, negative reaction? Some moderating conditions. Organ. Behav. Hum. Perform. 33, 204-213.

Heilman, M.E., McCullough, W.F., Gilbert, D., 1996. The other side of affirmative action: reactions of nonbeneficiaries to sex-based preferential treatment. J. Appl. Psychol. 81, 346-357.

Heilman, M.E., Rivero, J.C., Brett, J.F., 1991. Skirting the competence issue: effects of sex-based preferential selection on task choices of women and men. J. Appl. Psychol. 76, 99-105.

Heilman, M.E., Simon, M.C., Repper, D.P., 1987. Intentionally favored, unintentionally harmed? Impact of sex-based preferential selection on self-perceptions and self-evaluations. J. Appl. Psychol. 72, 62-68. 
Howard, G.S., 1994. Why do people say nasty things about self reports? J. Org. Behav.15, 399-404.

Human Resources Issues in the Hotel Industry. Retrieved from http://hubpages.com/hub/HumanResources-Issues-in-the-Hotel-Industry

Iverson, K., 2000. Managing for effective workforce diversity: identifying issues that are of concern to employees. Cornell Hospital. Q. 41 (2), 31-38.

Jablin, F.M., 1987. Organizational entry, assimilation, and exit. In: Jablin, F.M., Putnam, L.L., Roberts, K.H., Porter, L.H. (Eds.), Handbook of Organizational Communication. Sage Publications, Newbury Park, CA, pp. 679-740.

Jöreskog, K.G., Sörbom, D., 1996. LISREL 8 User’s Reference Guide. Scientific Software International, Chicago.

Kalev, A., Kelly, E., Dobbin, 2006. Best practices or best guesses? Assessing the efficacy of corporate Affirmative Action and diversity policies. Am. Sociol. Rev. 71(4), 589-617.

Kamens, D., 1977. Legitimating myths and the educational organization: the relationship between organizational ideology and formal structure. Am. Sociol. Rev.42, 208-219.

Kleiman, L.S., Faley, R.H., 1988. Voluntary affirmative action and preferential treatment: legal and research implications. Pers. Psychol. 41, 481-496.

Kravitz, D.A., Platania, J., 1993. Attitudes and beliefs about affirmative action: effects of target and of respondent sex and ethnicity. J. Appl. Psychol. 78, 928-938.

Leslie, L.M., Mayer, D.M., Kravitz, D.A., 2014. The stigma of affirmative action: a stereotyping-based theory and meta-analytic test of the consequences for performance. Acad. Manage. J. (forthcoming).

MacLean, T., Behnam, M., 2010. The dangers of decoupling: the relationship between compliance programs, legitimacy, perceptions, and institutionalized misconduct. Acad. Manage. J. 53 (6), 1499-1520.

MacVicar, A., Graham, M., Ogden, S., Scott, B., 2000. Women and flexibility in the Scottish leisure industry. Int. J. Contemp. Hospital. Manage. 12 (6), 380-383. 
Meyer, J.W., Rowan, B., 1977. Institutionalized organizations: formal structure as myth and ceremony.

Am. J. Sociol. 83, 340-363.

Meyer, J.W., Rowan, B., 1978. The structure of educational organizations. In: M.W. Meyer and Associates (Ed.), Environments and Organizations. Jossey-Bass, Inc., San Francisco, CA, pp. 78109.

Meyer, J.W., Scott, W.R., Deal, T.E., 1992. Institutional and technical sources of organizational structure: explaining the structure of educational organizations. In: Meyer, J.W., Scott, W.R. (Eds.), Organizational Environments: Ritual and Rationality. Sage Publications, Newbury Park, CA, pp. 45-70.

Nacoste, R.B., 1994. If empowerment is the goal. . .: affirmative action and social interaction. Basic Appl. Soc. Psychol. 15, 87-112.

Nacoste, R.W., 1987. Social psychology and affirmative action: the importance of process in policy analysis. J. Soc. Issues 43, 127-132.

Niederle, M., Segal, C., Vesterlund, L., 2013. How costly is diversity? Affirmative action in light of gender differences in competitiveness. Manage. Sci. 59 (1), 1-16.

Ng, C.W., Pine, R., 2003. Women and men in hotel management in Hong Kong: perceptions of gender and career development issues. IJHM 22, 85-102.

Northcraft, G.B., Martin, J., 1982. Double jeopardy: resistance to affirmative action from potential beneficiaries. In: Gutek, B. (Ed.), Sex Role Stereotyping and Affirmative Action Policy. Institute of Industrial Relations, University of California, Los Angeles, CA, pp. 81-130.

Ones, D.S., Viswesvaran, C., Reiss, A.D., 1996. Role of social desirability in personality testing for personnel selection: the red herring. J. Appl. Psychol. 81, 660-679.

Parker, C.P., Baltes, B.B., Christiansen, N.D., 1997. Support for affirmative action, jus-tice perceptions, and work attitudes: a study of gender and racial-ethnic group differences. J. Appl. Psychol. 82, 376-389.

Pfeffer, J., 1981. Power in Organizations. Pitman Publishing, Marshfield, MA. 
Pfeffer, J., Salancik, G.R., 1978. The External Control of Organizations. Harper and Row, New York, NY.

Pinar, M., McCuddy, M.K., Birkan, I., Kozak, M., 2011. Gender diversity in the hospitality industry: an empirical study in Turkey. Int. J. Hospital. Manage. 30, 73-81.

Plous, S., 1996. Ten myths about affirmative action. J. Soc. Issues 52, 25-31.

Robinson, R.K., Allen, B.M., Abraham, Y.T., 1992. Affirmative action plans in the1990s: a double edged sword? Public Pers. Manage. 21, 261-272.

Rogers, E.M., 1983. Diffusion of Innovations. Free Press, New York.

Salancik, G.R., Pfeffer, J., 1978. A social information processing approach to job attitudes and task design. Adm. Sci. Q. 23, 224-253.

Schmitt, N., 1994. Method bias: the importance of theory and measurement. J. Org. Behav. 15, 393-398.

Scott, W.R., 1987. The adolescence of institutional theory. Adm. Sci. Q. 32, 493-511.

Scott, W.R., 1995. Institutions and Organizations. Sage Publications, Newbury Park, CA.

Sherwyn, D., 2002. Arbitration of employment-discrimination lawsuits: legalities, practicalities, and realities. Cornell Hotel Restaur. Adm. Q. 43 (6), 62-72.

Shteynberg, G., Leslie, L.M., Knight, A.P., Mayer, D.M., 2011. But affirmative action hurts us! Race related beliefs shape perceptions of white disadvantage and policy unfairness. Organ. Behav. Hum. Decis. Process. 115, 1-12.

Slonaker, W.M., Wendt, A.C., Baker, B., 2007. Employment discrimination in the restaurant industry. Cornell Hotel Restaur. Adm. Q. 48 (1), 46-58.

Sourouklis, C., Tsagdis, D., 2013. Workforce diversity and hotel performance: a systematic review and synthesis of the international empirical evidence. IJHM 34,394-403.

Spector, P.E., 1994. Using self-report questionnaires in OB research: a comment on the use of a controversial method. J. Org. Behav. 15, 385-392.

Staw, B.M., Sutton, R.I., 1993. Macro organizational psychology. In: Murnighan, K. (Ed.), Social Psychology in Organizations. Prentice Hall, Englewood Cliffs, NJ, pp.350-384. 
Tilcsik, A., 2010. From ritual to reality: demography, ideology, and decoupling in a post-communist government agency. Acad. Manage. J. 53 (6), 1499-1520.

Tolbert, P.S., Zucker, L.G., 1996. The institutionalization of institutional theory. In: Clegg, S.R., Hardy, C., Nord, W.R. (Eds.), Handbook of Organizational Studies. Sage, Newbury Park, CA, pp. 175190.

Weaver, P., Wilborn, L., McCleary, K., Lekagul, A., 2003. Initiatives in the lodging industry: an exploratory analysis of underlying dimensions. J. Hospital. Tour. Res. 27 (2), 237-253.

Weick, K.E., 1993. Sensemaking in organizations: small structures with large con-sequences. In: Murnighan, K. (Ed.), Social Psychology in Organizations. Prentice Hall, Englewood Cliffs, NJ, pp. 10-37. 
Table 1. Measurement properties: reliabilities and items for each construct.

\begin{tabular}{|c|c|c|c|c|}
\hline Constructs and items & Standardized loading & $t$-Value & Cronbach's $\alpha$ & $\rho_{c}$ \\
\hline Institutional influence & & & .72 & .77 \\
\hline $\begin{array}{l}\text { (1) Regulating agencies such as the Equal Employment Opportunity } \\
\text { Commission (EEOC) are very important to the survival and legitimation of } \\
\text { organizations in today's business climate. }\end{array}$ & $.82^{a}$ & - & & \\
\hline $\begin{array}{l}\text { (2) Regulating agencies such as the EEOC are very important to help the } \\
\text { survival and legitimization of individuals in today's business climate. }\end{array}$ & .83 & 13.70 & & \\
\hline $\begin{array}{l}\text { (3) It is unnecessary to have agencies such as the EEOC to provide support and } \\
\text { protection for organizations in today's business climate, }{ }^{b, c}\end{array}$ & - & - & & \\
\hline $\begin{array}{l}\text { (4) It is unnecessary to have agencies such as the EEOC to provide support and } \\
\text { protection for individual workers in today's business climate, }{ }^{b, c}\end{array}$ & - & - & & \\
\hline (5) Regulating agencies such as the EEOC do not protect my best interests. ${ }^{b}$ & .48 & 9.03 & & \\
\hline Soctal influence & & & .78 & .80 \\
\hline (1) My friends greatly influence my perception of AA programs. & $.51^{\mathrm{a}}$ & - & & \\
\hline $\begin{array}{l}\text { (2) If I were looking for information about AA programs, I would seek the } \\
\text { advice of my friends. }\end{array}$ & 83 & 9.86 & & \\
\hline $\begin{array}{l}\text { (3) If I were looking for information about AA programs, I would seek the } \\
\text { advice of my family. }\end{array}$ & .77 & 9,67 & & \\
\hline $\begin{array}{l}\text { (4) If I were looking for information about AA programs, I would look to my } \\
\text { place of worship. }\end{array}$ & .69 & 9.24 & & \\
\hline General perceptions of $A A$ & & & .90 & .89 \\
\hline (1) Affirmative action (AA) is a good policy to have in effect in organizations. & $.76^{a}$ & - & & \\
\hline $\begin{array}{l}\text { (2) Based on what I know about AA, the goals of AA are good for today's } \\
\text { business climate. }\end{array}$ & .88 & 19.44 & & \\
\hline $\begin{array}{l}\text { (3) Employees should be actively involved in attempts to improve AA } \\
\text { programs at their place of work. }\end{array}$ & .72 & 14.40 & & \\
\hline $\begin{array}{l}\text { (4) I would be willing to work at an organization that actively uses AA } \\
\text { programs. }\end{array}$ & .74 & 14,08 & & \\
\hline $\begin{array}{l}\text { (5) All in all, I think AA plans bring about positive improvements to the work } \\
\text { environment in today's business climate }\end{array}$ & .88 & 17,07 & & \\
\hline Attitudes toward AA workers & & & .77 & .80 \\
\hline $\begin{array}{l}\text { (1) Workers hired through AA programs tend to be less qualified than those } \\
\text { hired without AA. }\end{array}$ & $.61^{2}$ & - & & \\
\hline (2) I do not (or would not) like working with AA hires in my place of work. ${ }^{b}$ & .73 & 10,78 & & \\
\hline $\begin{array}{l}\text { (3) Based on what I know about AA hires, they are no different than any other } \\
\text { worker and do not require special treatment or attention once they are hired } \\
\text { on the job. }{ }^{c}\end{array}$ & - & - & & \\
\hline (4) Having to work with AA hires would make me angry. ${ }^{b}$ & .72 & 10,71 & & \\
\hline $\begin{array}{l}\text { (5) Workers hired as a result of AA reflect poorly on the organization into } \\
\text { which they are hired. }\end{array}$ & .74 & 10,82 & & \\
\hline \multicolumn{5}{|l|}{ Fit indices: $\chi^{2}-210.01, \mathrm{df}-95, p<.001 ; \mathrm{GFI}-.94 ;$ CFI- $.98 ; \mathrm{NNFI}-.97$, RMSEA- .045} \\
\hline
\end{tabular}

Note: All $t$-values are significant at $p<.001 ; \rho_{\mathrm{c}}$, composite reliability.

a Item was fixed to 1 to set the scale of the construct.

b Item was presented in reverse form.

c Item was deleted after confirmatory factor analysis. 
Table 2. Descriptive statistics and $\Phi$-matrix for constructs.

\begin{tabular}{|c|c|c|c|c|c|c|c|}
\hline Constructs & Mean & SD & (1) & (2) & (3) & (4) & $\rho_{v}$ \\
\hline (1) Institutional influence & 3.50 & .81 & 1.00 & & & & .53 \\
\hline (2) Social influence & 2.47 & .87 & $.18^{-*}$ & 1.00 & & & .51 \\
\hline (3) General perceptions of AA & 3.44 & .81 & $.59^{\prime \prime}$ & $31^{* *}$ & 1.00 & & .67 \\
\hline (4) Attitudes toward AA workers & 3.47 & .65 & $.24^{-1}$ & .02 & $.41^{-\pi}$ & 1.00 & .59 \\
\hline
\end{tabular}

Note: $\rho_{v}$, average variance extracted,

$" p<01$. 
Table 3. Structural results of the indirect model and the direct model.

\begin{tabular}{|c|c|c|c|c|}
\hline \multirow[t]{2}{*}{ Paths } & \multicolumn{2}{|l|}{ Indirect model/full mediation } & \multicolumn{2}{|l|}{ Direct model/partial mediation } \\
\hline & Parameter estimate ( $t$-value) & Supported & Parameter estimate ( $t$-value) & Supported \\
\hline \multicolumn{5}{|l|}{ Indirect paths } \\
\hline Institutional influence $\rightarrow$ General perceptions of AA $(\gamma 11)$ & $.55\left(9.21^{-3}\right)$ & Yes & $.55\left(9.18^{-3}\right)$ & Yes \\
\hline Social influence $\rightarrow$ General perceptions of AA $(\gamma / 2)$ & $.21\left(3.91^{-m}\right)$ & Yes & $.22\left(4.02^{--}\right)$ & Yes \\
\hline General perceptions of AA $\rightarrow$ Attitudes toward AA workers ( $\beta_{21}$ ) & $.41\left(6.37^{-7}\right)$ & Yes & $.46\left(5.49^{-*}\right)$ & Yes \\
\hline \multicolumn{5}{|l|}{ Direct paths } \\
\hline Institutional influence $\rightarrow$ Attitudes toward AA workers $\left(\gamma_{21}\right)$ & - & - & $.00\left(.02^{\mathrm{ns}}\right)$ & No \\
\hline Social influence $\rightarrow$ Attitudes toward AA workers $\left(\gamma_{22}\right)$ & - & - & $-.16\left(-2.61^{-17}\right)$ & Yes \\
\hline \multicolumn{5}{|l|}{ Goodness-of-fit measures } \\
\hline$\chi_{(\mathrm{df})}^{2}$ & $216.69_{(97)}$ & & $210,01_{(95)}$ & \\
\hline GFI & .94 & & .94 & \\
\hline CFI & .98 & & .98 & \\
\hline NNFI & .97 & & .97 & \\
\hline RMSEA & .055 & & .054 & \\
\hline \multicolumn{5}{|l|}{ Variance explained $\left(R^{2}\right)$} \\
\hline General perceptions of AA & 39 & & .39 & \\
\hline Attitudes toward AA workers & .17 & & .19 & \\
\hline Comparison $\left(\chi_{\text {difference }}^{2}\right)$ & \multicolumn{4}{|c|}{$6.68(2), p<, 05$, retain direct model (partial mediation) } \\
\hline
\end{tabular}

n.s., non-significant.

" $p<.01$.

$\cdots p<.001$. 


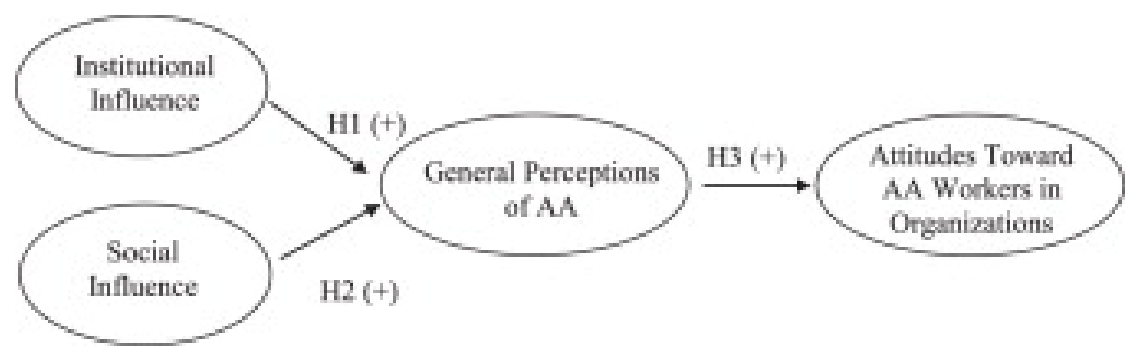

Figure 1. Hypothesized model of institutional and social influences on perceptions of affirmative action. 


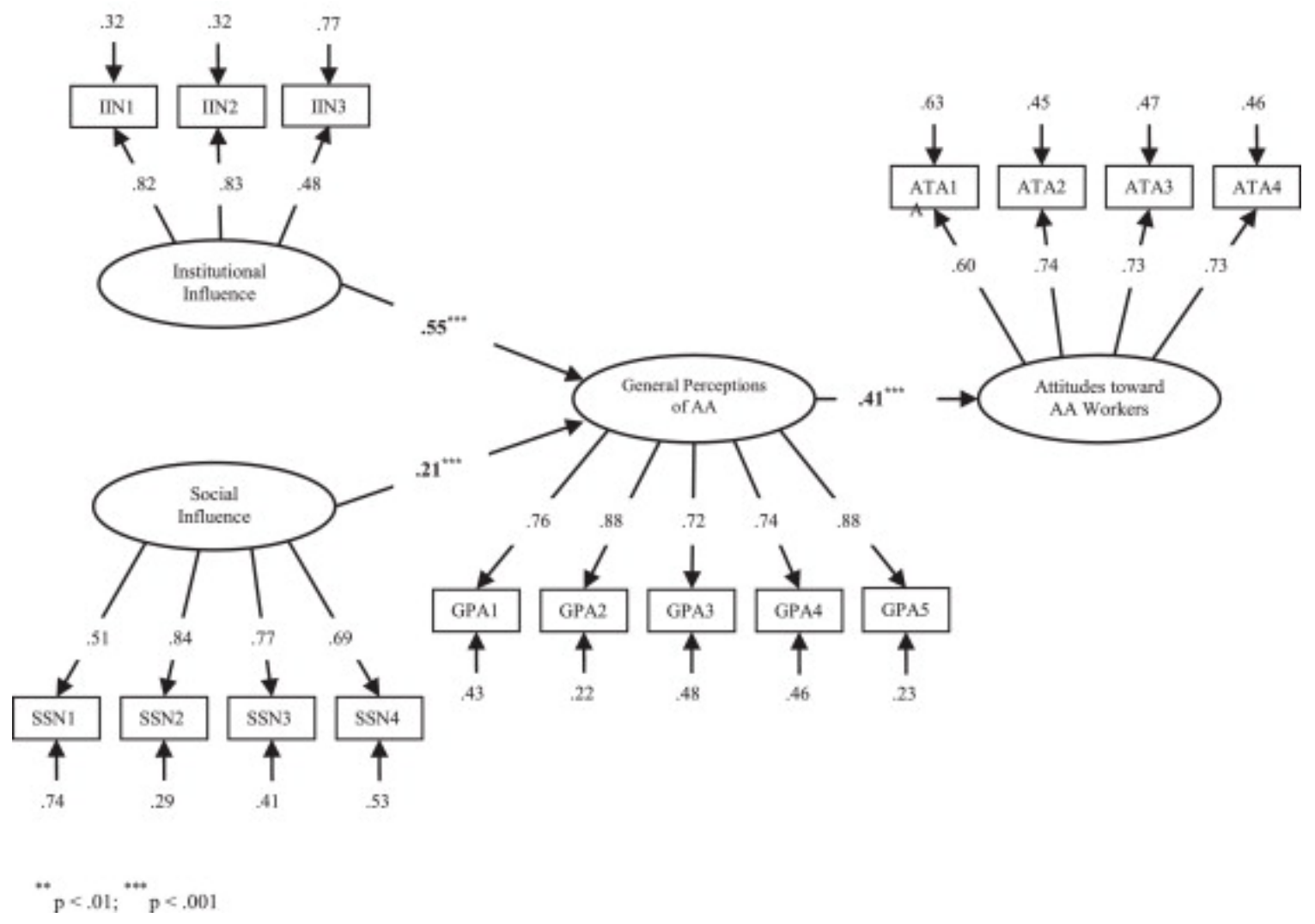

Figure 2. Indirect model of institutional and social influences on affirmative action. 


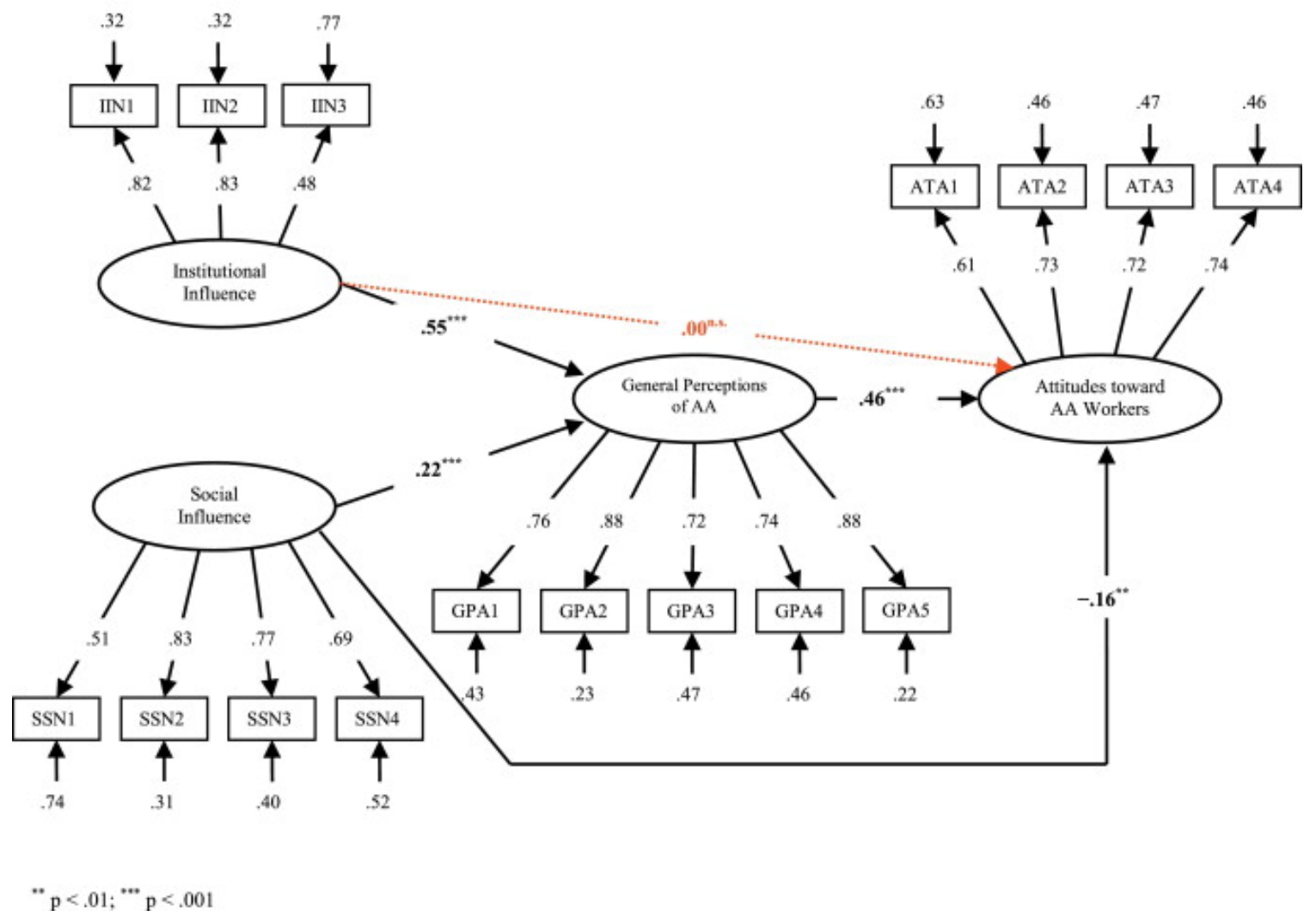

Figure 3. Direct model of institutional and social influences on affirmative action. 